\title{
Validity and Reliability of the Oral Health Impact Profile Instrument (OHIP-14) in Adolescents
}

\author{
Marise Fagundes Silveira' ${ }^{1}$ (D) https://orcid.org/0000-0002-8821-3160 \\ Lucinéia de Pinho ${ }^{1}$ (D) https://orcid.org/0000-0002-2947-5806 \\ Maria Fernanda Santos Figueiredo Brito ${ }^{1}$ (1) https://orcid.org/0000-0001-5395-9491
}

\begin{abstract}
Oral conditions impact on the individual's health and quality of life. The use of a valid and reliable instrument provides accuracy in the measurement of this impact. This study aimed to assess the evidences of validity and reliability of the Oral Health Impact Profile instrument (OHIP-14) in adolescents. A total of 763 adolescents participated in the study. The OHIP-14, the 12-Item Short-Form Health Survey (SF-12) and intraoral examinations were used. In the confirmatory factor analysis, the OHIP-14 showed acceptable adjustment indexes: $\mathrm{CFI}=0.957$; GFI $=0.959$ and RMSEA $=0.063$. Normative oral health conditions show significant association with OHIP-14 scores. Significant correlation was observed between the total OHIP-14 score and the scores of self-perception of oral health $(p<0.001)$ and the physical and mental dimensions of the SF-12 $(p<0.001)$. The Cronbach alpha coefficient was adequate $(\alpha=0.87)$. OHIP-14 was showed satisfactory validity and reliability, subsiding its use in studies that assess the self-perception of oral health for this population.
\end{abstract}

Keywords: adolescents, factor analysis, odontology, scales

\section{Validade e Confiabilidade do Instrumento Oral Health Impact Profile (OHIP-14) em Adolescentes}

\begin{abstract}
Resumo: As condições bucais impactam na saúde e na qualidade de vida do indivíduo. O uso de instrumento válido e confiável propicia acurácia na medida desse impacto. Este estudo teve como objetivo avaliar as evidências de validade e confiabilidade do instrumento Oral Heath Impact Profile (OHIP-14) em adolescentes. Participaram do estudo 763 adolescentes. Foram utilizados o OHIP-14, o 12-Item Short-Form Health Survey (SF-12) e exames intrabucais. Na análise fatorial confirmatória, o OHIP-14 apresentou índices de ajustes aceitáveis: $\mathrm{CFI}=0,957$; GFI $=0,959$ e RMSEA=0,063. As condições normativas de saúde bucal apresentaram associação significativa com os escores do OHIP-14. Observou-se correlação significativa do escore total do OHIP-14 com os escores da autopercepção da saúde bucal $(p<0.001)$ e as dimensões física e mental do SF-12 $(p<0.001)$. O coeficiente de alfa de Cronbach foi adequado $(\alpha=0,87)$. O OHIP-14 apresentou validade e confiabilidade satisfatórias, evidência que subsidia a sua utilização em estudos que avaliam a autopercepção da saúde bucal para essa população.
\end{abstract}

Palavras-chaves: adolescentes, análise fatorial, escalas, odontologia

\section{Validez y Confiabilidad del Instrumento Oral Health Impact Profile (OHIP-14) en Adolescentes}

\begin{abstract}
Resumen: Las condiciones bucales afectan a la salud y la calidad de vida del individuo. La utilización de un instrumento válido y fiable favorece la precisión en la medición de ese impacto. El presente estudio tuvo como objetivo evaluar las evidencias de validez y confiabilidad del instrumento Oral Heath Impact Profile (OHIP-14) en adolescentes. En el estudio participaron 763 adolescentes. Se utilizaron el OHIP-14, el 12-Item Short-Form Health Survey (SF-12) y el chequeo intrabucal. En el análisis factorial confirmatorio, el OHIP-14 presentó índices de regulación aceptables: $\mathrm{CFI}=0,957$; GFI $=0,959$ y RMSEA $=0,063$. Las perceptivas de salud bucal presentaron una asociación significativa con los puntajes del OHIP-14. Se observó una correlación significativa del puntaje total del OHIP-14 con los puntajes de la autopercepción de la salud bucal $(p<0.001)$ y las dimensiones física y mental de SF-12 $(p<0.001)$. El coeficiente de alfa de Cronbach fue adecuado $(\alpha=0,87)$. El OHIP-14 tuvo validez y confiabilidad satisfactorias, lo que posibilita su utilización en estudios que evalúan la autopercepción de esa población sobre la salud bucal.
\end{abstract}

Palabras clave: adolescentes, análisis factorial, escalas, odontología

${ }^{1}$ Universidade Estadual de Montes Claros, Montes Claros-MG, Brazil

Correspondence address: Marise Fagundes Silveira. Universidade Estadual de Montes Claros. Vila Mauriceia. Montes Claros-MG, Brazil. CEP 39.401-089.

E-mail: ciaestatistica@yahoo.com.br
Oral health conditions are considered an important and inseparable part of people's general health and quality of life, by the multidimensionality and by the individual and social impact (Afonso \& Silva, 2015). In adolescents, studies 
evidence that oral health problems cause negative impact on their daily performance and quality of life (Barbosa, Mialhe, Castilho, \& Gavião, 2010; Oliveira et al., 2015; Peres, Cascaes, Leão, Côrtes, \& Vettore, 2013).

In the national scenario, oral diseases in adolescents are prevalent. A survey on Oral Health conducted with 5,445 adolescents aged from 15 to 19 years in Brazil verified that $46.6 \%$ had dental cavities, $17.4 \%$ showed tooth loss due to cavities, $15 \%$ occlusion problems, $35 \%$ bleeding on probing, and $25 \%$ reported toothache in the last six months (Peres et al., 2013). These conditions have been associated to a greater negative impact on the quality of life in this age group (Oliveira et al., 2015; Peres et al., 2013).

In the analysis of the oral health of adolescents, in addition to clinical measures (objective and normative conditions), other measures have been used, related to the self-perception on their health and on the impact that oral diseases cause on their daily life (Aubert et al., 2014; Silva et al., 2016; Silveira, Marôco, Freire, Martins, \& Marcopito, 2014; Tuchtenhagen et al., 2015). Data on the self-perception of oral health at an early age are important, reflect the subjective experiences of the individuals, its functionality and the related social and cultural values, which might modulate the behaviors related to oral health care (Bauman, Souza, Bauman, \& Flório, 2018).

This type of evaluation reflects a larger view of dental conditions of the individual. Oral health is not only directed to the absence or the cure of diseases, but it is also focused on the functional, social and psychological well-being of people. To do so, there is the need to determine the integral repercussion of changes present in the oral cavity (Barbosa et al., 2010).

The measuring of this latent construct - self-perception of the impact of oral health in quality of life - demands the use of psychometric scales that favor the evaluation of plausibility of explanatory theoretical models (Hutz, Bandeira, \& Trentini, 2015). Among the assessment instruments of the impact of oral health with this approach, one of the most used, in different cultures and sociodemographic profiles, is the Oral Health Impact Profile (OHIP) developed in Australia (Slade, 1997), with the purpose of assessing disfunctions, discomfort and disabilities attributed to oral conditions. This information aims to complement the traditional indicators of oral epidemiology of clinical diseases, providing a profile of the impact of the disease in populations and the efficacy of the health services in reducing these impacts (Slade, 1997).

OHIP-14 is considered a good indicator to capture perceptions and feelings of the individuals on their own oral health and their expectations regarding treatments and dental services. It is one of the most widespread self-assessment questionnaires of oral health and has been used by many researchers due to its practicality, ease of use, reduced number of questions and validity (Zucoloto, Marôco, \& Campos, 2014). The instrument was translated and validated in the international (Deshpande \& Nawathe, 2015; MonteroMartín, Bravo-Pérez, Albaladejo-Matínez, HernándezMartín, \& Rosel-Gallardo, 2009; Papagiannopoulou, Oulis, Papaioannou, Antonogeorgos, \& Yfantopoulos, 2012;
Skośkiewicz-Malinowska, Kaczmarek, Ziętek, \& Malicka, 2015) and national scenario (Campos, Carrascosa, Zucoloto, \& Maroco, 2014; Cohen-Carneiro et al., 2010).

The psychometric evaluation of the OHIP-14 was performed in different populations and age groups. The value of the Cronbach alpha coefficient was above 0.90 for all items of the instrument in Poland (Skośkiewicz-Malinowska et al., 2015), and in Greece (Papagiannopoulou et al., 2012), and above 0.89 in Spain (Montero-Martín et al., 2009) and in Brazil (Cohen-Carneiro et al., 2010). The correlation coefficients item-total of the instrument varied from 0.44 to 0.76 in Greece (Papagiannopoulou et al., 2012). Significant associations were found between the total OHIP-14 score and the oral health conditions and self-perception of the oral health state in Greece (Papagiannopoulou et al., 2012) and in Spain (Montero-Martín et al., 2009). The stability of the instrument was observed in a study performed in Brasil (Cohen-Carneiro et al., 2010) and in Portugal (Afonso, Silva, Meneses, \& Frias-Bulhosa, 2017).

In the validation process of an instrument, it is necessary that its reliability and validity be demonstrated in populations of different age groups, sociodemographic conditions and oral health (Barbosa et al., 2010). In literature, studies assessed the psychometric properties of OHIP-14 (Awad, AlShamrany, Locker, Allen, \& Feine, 2008; Cohen-Carneiro et al., 2010; Ferreira, Loureiro, \& Araújo, 2004; MonteroMartín et al., 2009), and most were conducted with adults and seniors (Cohen-Carneiro et al., 2010; Montero-Martín et al., 2009; Zucoloto et al., 2014). There is a gap in relation to the validation of OHIP-14 in the adolescent population.

The validation of the OHIP-14 aimed specifically for the adolescent population may provide a more accurate measurement of the impact of oral conditions on general health and on quality of life (Barbosa et al., 2010; Zucoloto et al., 2014), considering the regional and cultural differences involved in the self-perception of oral health. In this sense, this study aimed to assess the evidences of validity and reliability of the instrument Oral Heath Impact Profile (OHIP-14) in adolescents.

\section{Method}

This is a study of validation and reliability of the instrument OHIP-14 in adolescents. The data used were obtained from an epidemiological survey of the oral health conditions of the population of the municipality of Montes Claros-MG.

\section{Participants}

The target population was constituted of 15 to 19 -yearold adolescents living in the urban and rural areas of the Municipality of Montes Claros, Minas Gerais, Brazil, in 2009. Because it is a study which aimed to estimate the prevalence of several oral diseases, the sample size was established, considering: 0.50 prevalence of oral diseases in adolescents; range of $95 \%$ of confidence and accuracy level of $5.5 \%$. The 
correction for finite population and for the design effect was performed, adopting a deff equal to 2.0. Also, an addition of $20 \%$ was established to compensate the possible absences of responses and losses. The calculations evidenced the need to perform examinations and interviews with, at least, 761 individuals, being 365 (48.0\%) male and 396 (52.0\%) female.

The number of adolescents, previously defined, for the participation in the epidemiological study met the requirements for the sampling size in a study of psychometric validation through the Confirmatory Factor Analysis (CFA) (Hair, Anderson, TaV lack, 2009; Marôco, 2014) of the OHIP-14. The participation of at least 525 adolescents was estimated, considering the number of parameters to be estimated in the measurement model in evaluation, defined in 35 (14 factor weights of dimensions, 7 variances of dimensions and 14 variances of errors) and the ratio of 15 interviews by estimated parameter. It is worth emphasizing that the factor weights of the errors were set at 1 , indicating that these latent variables have the same metric of the corresponding manifest variables.

\section{Instruments}

The research used a questionnaire which contemplated a file for collection of demographic and clinical data and the validated instruments: Oral Health Impact Profile (OHIP14) (Slade, 1997) and 12-Item Short-Form Health Survey (SF-12) (Ware, Kosinski, \& Keller, 1996). The instruments will be described below.

File for demographic and clinical data: contemplated the characterization of adolescents regarding the demographical variables, such as sex (male; female) and age (in years), and oral health variables, such as presence of dental cavity, presence of restored teeth, number of lost teeth, Community Periodontal Index (CPI), Dental Aesthetic Index (DAI), presence of plaque and need for prosthesis.

Oral Health Impact Profile (OHIP-14): composed of 14 items that assess seven different dimensions, considering the perception of the individual in relation to the impact of oral conditions in the physical, psychological and social well-being in the last six months. Each of the 14 OHIP14 items has a set of possible answers distributed in a Likert scale $(4=$ always, $3=$ frequently, $2=$ sometimes, $1=$ seldom and $0=$ always), which represents the frequency that the individual perceives the impact of oral health on seven dimensions: functional limitation, physical pain, psychological discomfort, physical disability, psychological disability, social disability and handicap (Slade, 1997).

12-Item Short-Form Health Survey (SF-12): is an instrument composed of 12 items that assess the perception of the individual in relation to the aspects of their health in the past four weeks, considering functional capacity, physical aspects, pain, general health state, vitality, social aspects, emotional aspects and mental health. Each of the 12 items has a set of possible answers distributed in a Likert scale, and, from the application of an algorithm specific to the questionnaire, two domains were calculated: physical
(Physical Component Summary or PCS) and mental (Mental Component Summary or MCS). These scores varied in a scale from zero to 100 , with higher values correlated to better quality of life (Ware et al., 1996).

\section{Procedures}

Data collection. The collected data were related to the interviews and to the oral exams performed by trained dentist surgeons, aided by people taking notes. Intraoral exams were performed in a wide scape, with natural lighting, with mirror and CPI probe. The study was developed in the households of the participants, selected by probability sampling by conglomerates in two stages. In the first stage, simple random sampling was adopted and 55 of the 276 urban census tracts and two of the eleven rural areas of Montes Claros were selected, according to the data estimated from the results of the census conducted in 2000 (IBGE, 2000). In the second stage, by simple random sampling, approximately six blocks in each of the 55 tracts were drawn. In the rural zone, there was only one selection stage, and all the households located at a distance of up to 500 meters of an institution of reference (such as schools or churches) were selected. The households situated in the selected areas were sequentially visited, and adolescents aged 15-19 years-old were invited to participate.

To record the interviews, each person taking notes used a handheld PC, in which an app was installed, especially developed for collection and simultaneous construction of the database of the SBMOC project. At the end of each collection day, the data stored in the handheld PCs were transferred to a central computer. At the end of the collection, data were exported to a statistical software and, subsequently, they were checked, reviewed and corrected.

Data analysis. The characterization of the adolescents regarding demographic and oral health variables was performed through frequency distribution. The descript analysis of the OHIP-14 was conducted by frequency distribution, mean and standard deviation of its 14 items and of the total score, obtained by the sum of the values attributed to the 14 items of the scale, which can vary from 0 to 56 .

Evidences of the validity of OHIP-14 were assessed by the analysis of construct validity (factor, convergent and discriminant validity), criterion validity (concurrent and divergent) and reliability (analysis of internal consistency and reproducibility). For the factor validity, the confirmatory factor analysis (CFA) was used, which assessed the factor structure of the model, with seven dimensions, proposed by Slade (1997). As an quality indicator of the local adjustment, the factor weight $(\lambda \geq 0.50)$ was used, and, to assess the quality of the global adjustment of the model, the Chi-square ratio was used by the degree of freedom $\left(X^{2} / g . l\right)$, the Bentler comparative fit index (CFI), the goodness of fit index (GFI) and the root mean square error of approximation (RMSEA). The fit of the model was considered adequate when $X^{2} / g . l \leq 3.0$, CFI and GFI $\geq 0.90$ and RMSEA $\leq 0.10$ (Marôco, 2014).

The convergent validity was estimated by average variance extracted (AVE) and composite reliability (CR). 
The values of AVE $\geq 0.5$ and $\mathrm{CR} \geq 0.7$ were considered adequate (Marôco, 2014). For the discriminant validity, the general OHIP-14 score was compared among the population subgroups that hypothetically should show different levels of impact of oral health, using the Mann-Whitney test (significance level $\alpha=0.05$ ). The subgroups were defined from the following normative conditions of oral health: presence of caries, presence of restored teeth, number of lost teeth, CPI, DAI, presence of plaque and need for prosthesis.

The concurrent criterion validity was verified by the correlation between the total OHIP-14 score and the selfperception of the quality of oral health, assessed through the following question: "How do you classify your oral health?" (very bad $=1$, bad $=2$, regular $=3$, good $=4$; very good $=5$ ). To verify the divergent criterion validity, the correlations between the total OHIP-14 score and the scores of the physical (PCS) and mental (MCS) domains of the questionnaire 12-Item Short-Form Health Survey (SF-12) (Ware et al., 1996). All correlations were assessed by the Spearman's correlation coefficient, and the ones with value $p \leq 0.05$ were considered significant.

The internal consistency of the OHIP-14 was assessed by the Cronbach alpha coefficient for each dimension of the instrument and for the global scale, adopting a minimum value of 0.70 as a satisfactory internal consistency (Hair et al., 2009). To assess the reproducibility of the instrument, the questionnaire was applied and reapplied within a week to a convenience sample of 60 volunteers, and the weighted Kappa coefficient was calculated for each item of the instrument. For the interpretation of the Kappa coefficient, the following range cuts were adopted: $0-0.19=$ poor agreement; $0.20-0.39=$ slight agreement; $0.40-0.59=$ moderate agreement; $0.60-0.79=$ substantial agreement; and $0.80-1.00=$ almost perfect agreement (Landis \& Koch, 1977). The analyses were conducted with the aid of the Predictive Analytics Software (PASW®), version 23.0 (Norusis, 2012) and the Analysis of Moments Structures software (AMOS®), version 23.0 (Arbuckle, 2014).

\section{Ethical Considerations}

This research project was conducted within the standards required by the Declaration of Helsinki and approved by the Research Ethics Committee (Opinion no. 318/06). The participants and their respective guardians signed the Assent Form and the Informed Consent Form, respectively, in agreement to participate voluntarily in the study, before having access to the questionnaire.

\section{Results}

763 adolescents participated in the study (99.6\% from the urban area), most were female $(52.7 \%)$ and the average age was 17.1 years $(\mathrm{SD} \pm 1.5)$. The overall OHIP-14 score in this population showed an average of $4.1 \pm 6.4$.

The result of confirmatory factor analysis of OHIP14 is shown in Figure 1. The values of the standardized factor weights of the items were described in the adjusted measurement model with seven latent factors. The model fitting indices were acceptable: $\mathrm{CFI}=0.957$; $\mathrm{GFI}=0.959$; RMSEA $=0.063$, except for $\mathrm{X}^{2} / d f=3.973$.

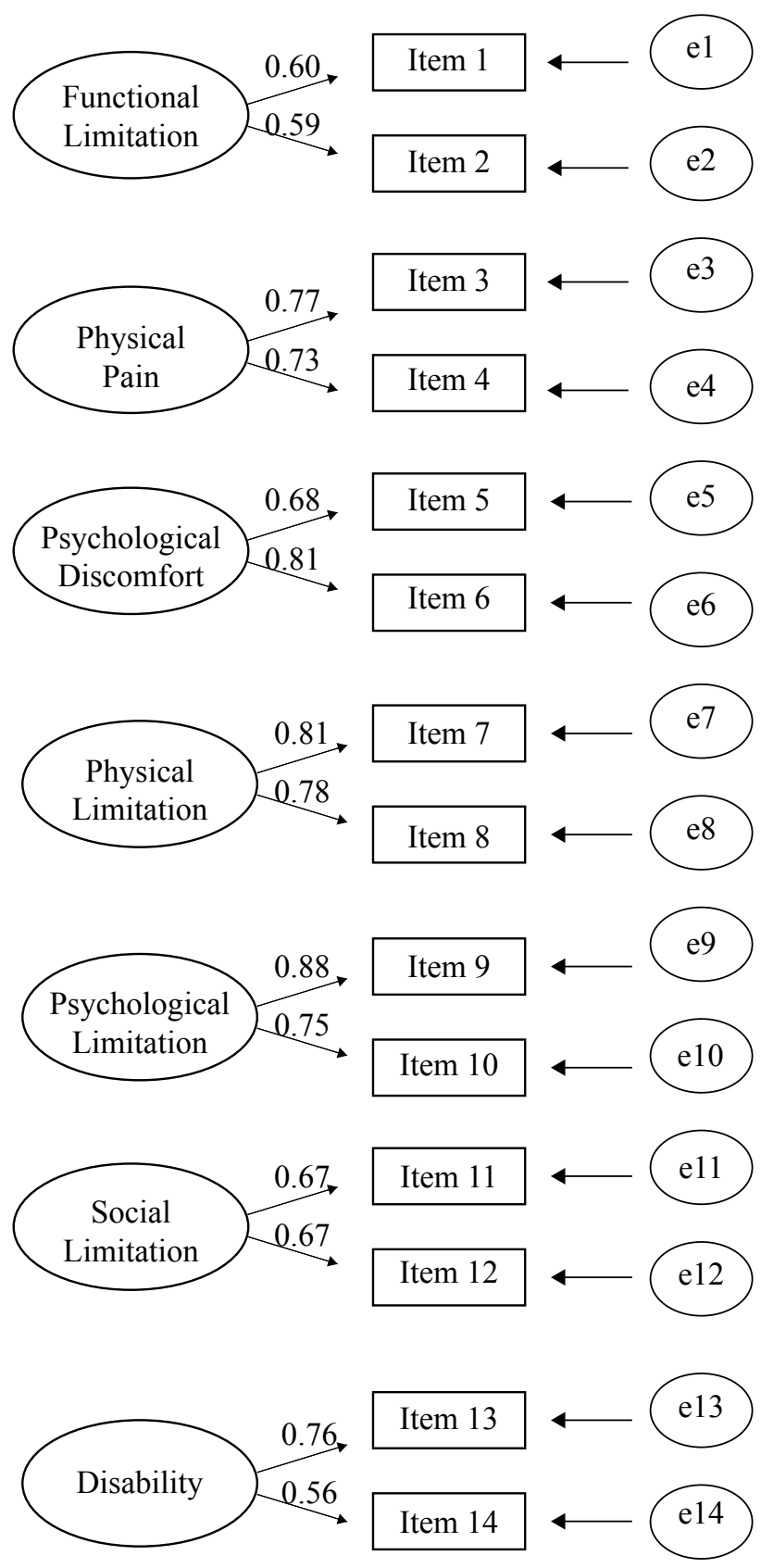

Figure 1. Factor model generated by the Confirmatory Factor Analysis of the Oral Health Impact Profile questionnaire version of 14 items (OHIP-14), with the respective factor loads and errors associated to each item of the instrument. *"e"=error.

The convergent validity indicators - AVE and CR were adequate in their dimensions, except for the functional limitation dimension, which showed adjacent values (AVE $=$ $0.47, \mathrm{CR}=0.64$ ), as shown in Table 1 . 
Table 1

Average Variance Extracted (AVE), Composite Reliability (CR) of the Dimensions of the OHIP-14 Instruments among 15 to 19-year-old adolescents

\begin{tabular}{lcc}
\hline & \multicolumn{2}{c}{ Convergent validity } \\
OHIP-14 dimensions & AVE & CR \\
\cline { 2 - 3 } Functional limitation & 0.47 & 0.64 \\
Physical pain & 0.69 & 0.82 \\
Psychological discomfort & 0.69 & 0.81 \\
Physical limitation & 0.76 & 0.86 \\
Psychological limitation & 0.78 & 0.88 \\
Social limitation & 0.58 & 0.73 \\
Handicap & 0.57 & 0.72 \\
Overall Impact & 0.82 & 0.96 \\
\hline
\end{tabular}

As can be seen in Table 2, the presence of dental cavity, restored teeth, number of lost teeth, the CPI, CAI, presence of plaque and the need for prosthesis show significant association with the OHIP-14 scores $(p<0.05)$, demonstrating the discriminant validity of the instrument. Also, significant correlations of the OHIP-14 with the self-perception of oral health $(\mathrm{R}=-0.31 ; p<0.001)$ and the physical $(\mathrm{R}=-0.30$; $p<0.001)$ and mental dimensions $(\mathrm{R}=-0.27 ; p<0.001)$ of the SF-12 were observed, demonstrating the concurrent and divergent criterion validity.

Table 2

Frequency Distribution, Median and Interquartile Range of the Total OHIP-14 score, according to the Normative Conditions of Oral Health among 15 to 19-year-old Adolescents

\begin{tabular}{|c|c|c|c|c|}
\hline Oral conditions & & $n(\%)$ & Median & IQ range \\
\hline \multirow{2}{*}{ Presence of dental cavity } & No & $483(63.3)$ & $0.0^{*}$ & $0.0-4.0$ \\
\hline & Yes & $280(36.7)$ & $3.0^{*}$ & $0.0-10.0$ \\
\hline \multirow{2}{*}{ Presence of restored teeth } & No & $711(93.2)$ & $0.0^{*}$ & $0.0-4.0$ \\
\hline & Yes & $52(6.8)$ & $2.0^{*}$ & $0.0-6.0$ \\
\hline \multirow{2}{*}{ Number of lost teeth } & None & $642(84.1)$ & $1.0 * *$ & $0.0-5.0$ \\
\hline & $\geq 1$ & $121(15.9)$ & $2.0 * *$ & $0.0-9.0$ \\
\hline \multirow{2}{*}{ Periodontal condition (CPI) } & Healthy & $517(67.6)$ & $0.0^{*}$ & $0.0-4.0$ \\
\hline & Unhealthy & $246(32.3)$ & $2.0^{*}$ & $0.0-8.0$ \\
\hline \multirow{2}{*}{ Malocclusion (DAI) } & Mild/moderate & $661(86.6)$ & $1.0 * *$ & $0.0-5.0$ \\
\hline & Serious/Very serious & $102(13.4)$ & $3.0 * *$ & $0.0-7.0$ \\
\hline \multirow{2}{*}{ Plaque $^{a}$} & Absent & $454(59.7)$ & $0.0^{*}$ & $0.0-4.0$ \\
\hline & Present & $306(40.3)$ & $2.0^{*}$ & $0.0-6.0$ \\
\hline \multirow{2}{*}{ Need for prosthesis } & No need & $711(93.2)$ & $1.0 * *$ & $0.0-5.0$ \\
\hline & Need & $52(6.8)$ & $4.0 * *$ & $0.0-10.0$ \\
\hline
\end{tabular}

Note. IQ Int. = Interquartile Range; Mann-Whitney test: ${ }^{*} p=0.0001 ; * * p 0.05$. The variable plaque has lost data.

Table 3 shows the values of Cronbach alpha coefficient, of the item-total correlation and Kappa coefficient of the OHIP-14 Instrument. The measure of internal consistency of the global scale of OHIP-14 showed a Cronbach alpha value equal to $0.87\left(\mathrm{CI}_{95 \%} 0.86-0.89, p<0.001\right)$. This parameter varied from 0.52 to 0.76 between the seven dimensions. It was observed that the Cronbach alpha coefficient value, when each item was removed from the analysis, varied from 0.85 to 0.87 , remaining less than or equal to the value for global scale. The correlation between each item of the instrument and its total score was positive, with values varying from 0.31 to 0.70 . The measure of reproducibility of the OHIP14 items, assessed by the weighted Kappa coefficient, varied from 053 to 1.00 . 
Table 3

Cronbach Alpha Coefficient, Item-Total Correlation and Kappa Coefficient of the OHIP-14 Instrument among 15 to 19-year-old Adolescents

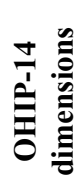

Functional limitation

2. Have you been feeling that the taste of food has
gotten worse?

Physical pain

3. Have you been feeling pain in your mouth or teeth?

4. Have you been feeling discomfort while eating?

Psychological discomfort

5. Have you been feeling worried?

6. Have you been feeling stressed?

7. Has your eating been impaired lately?

limitation

8. Have you had to stop your meals?

Psychological limitation

9. Have you been finding it difficult to relax?

10. Have you been feeling embarrassed?

Social limitation

11. Have you been getting angry with other people?

12. Have you been having difficulties to perform your daily activities?

Handicap

13. Have you been feeling that your life, in general, got worse?

14. Have you been feeling completely unable to perform your daily activities?

$$
0.52
$$

$(0.45-0.58)$

0.74

$(0.70-0.77)$

0.70

(0.65-0.74)

0.76

(0.73-0.80)

0.47

(0.39-0.54)

0.60

(0.54-0.66)

(0.5

0.54

$(0.47-0.60)$

0.87

(0.85-0.89)

General scale

Note. $\mathrm{CI}=$ Confidence Interval.

\section{Discussion}

This study assessed the evidences of validity and reliability of the OHIP-14 in a population of adolescents. The findings demonstrate that the factor structure of the OHIP-14 model with seven latent factors showed acceptable adjustment indexes. The results revealed the discriminant validity of the instrument based on the normative conditions of oral health. The relation of the OHIP-14 scores with the self-perception of oral health and the SF-12 scores demonstrated the concurrent and divergent criterion validities, respectively. The measure of internal consistency of the global scale was satisfactory. In addition, the OHIP-14 version indicated adequate reproducibility.
The scales, due to population differences and to transformations that occur in the individuals throughout the years, require the analysis of its structure, continuously. In this way, the evidences of validity and reliability of an instrument ensure greater precision of measurement. Qualified instruments provide to researchers new methodological resources and, in the clinical practice, direct diagnostic investigations and interventions with greater safety (Reppold, Gurgel, \& Hutz, 2014). Previous studies have used scales to assess the impact of oral diseases on the quality of life of the individuals. The OHIP-14 is a useful instrument to assess this impact (Afonso et al., 2017; Campos et al., 2014; Colussi, Hugo, Muniz, \& Rösing, 2017; Oliveira et al., 2015; Silveira et al., 2014). 
Research projects on the international (Afonso et al., 2017; Montero-Martín et al., 2009; Rener-Sitar, Petričević, Čelebić, \& Marion, 2008) and national scenarios (CohenCarneiro et al., 2010; Zucoloto et al., 2014) evidenced that the OHIP-14 is a valid and reliable instrument for the investigation on oral health conditions. This study ratified the presence of validity and reliability in this instrument, specifically among teenagers, in which there is a high negative impact of oral diseases, as observed in a national survey with a sample of 5,445 researchers in this age group (Peres et al., 2013). The evidence of validity and reliability of the OHIP-14 in this population can contribute to a more accurate measurement of the impact of oral health conditions (Barbosa et al., 2010).

In this study, the presence of construct validity of the OHIP-14 was observed. In the factor analysis, the assessed instrument confirmed the factor structure of its version with seven latent dimensions (Slade, 1997), whose factor weights of the items showed high and significant values, indicating that they measure the to-be-measured latent factors-seven dimensions of the OHIP-14. This finding indicates that the items have a good behavioral representation of the latent trait (Hutz et al., 2015; Pasquali, 2009). Through this analysis, it was possible to verify that the assessed construct - impact of oral diseases on quality of life - is explained by the seven dimensions of the OHIP-14 (Hutz et al., 2015). These results can subsidize the choice of this structure of the instrument for the studied population.

Regarding the quality of the fit, the measurement model was adequate for the fitness level for the CFI, GFI and RMSEA indexes. Although the value of the absolute index $\mathrm{X}^{2} / D F$ was above the value adopted as acceptable, there was no severe violation $\left(\mathrm{X}^{2} / D F>5.00\right)$. In this sense, the tested stability of the model meets the expectations of goodness of fit referred by Marôco (2014).

Convergent validity was satisfactory, except for the "functional limitation" dimension. This finding agrees with what was verified in a previous study (Zucoloto et al., 2014), in which the convergent validity was not satisfactory in the "functional limitation" and in the "psychological discomfort" dimensions.

The OHIP-14 also showed discriminant validity by being able to discriminate the studied subjects, since individuals with oral problems, such as the presence of dental cavity, restored teeth, lost teeth, periodontal alteration, malocclusion, presence of plaque and need for prosthesis, noticed a greater impact of oral health conditions in the quality of life of adolescents. These results corroborate the findings of Slade (1997), who showed that higher OHIP scores were obtained when it was used in individuals who had less favored clinical dental conditions. Vyas, Nagarajappa, Dasar and Mishra (2018), in a study on OHIP-14 validity, observed that the clinical parameters, such as oral hygiene state and caries, might change the perception of quality of life of an individual.

The OHIP-14 also showed criterion validity, since its total score showed significant correlation with the scores of self-perception of oral health - concurrent validity - and of the SF-12 - divergent validity. These findings were also observed in previous studies developed with adolescents (Ferreira et al., 2004) and in other populations (CohenCarneiro et al., 2010; Montero-Martín et al., 2009; Zucoloto et al., 2014). This reduced version did not affect the validity of the OHIP for the adolescent population, which has been a concern described in literature (Awad et al., 2008).

Regarding the reliability of the OHIP-14, a satisfactory internal consistence was observed, with the Cronbach alpha coefficient $\left(0.87 ; \mathrm{CI}_{95 \%} 0.86-0.89 ; \mathrm{p}<0.001\right)$ above the acceptable level (Hair et al., 2009), which evidences items highly intercorrelated in the measure of the same latent construct and its ability to measure without errors (Hair et al., 2009; Pasquali, 2009). The OHIP-14 reliability was also observed in other validation studies of this instrument in adolescents (Ferreira et al., 2004) and in other age groups (Cohen-Carneiro et al., 2010; Montero-Martín et al., 2009; Rener-Sitar et al., 2008).

The Cronbach alpha values below 0.70 in some dimensions - functional limitation, psychological limitation, social limitation and handicap - in this study might be due to the low number of items that compose them (Awad et al., 2008), which might be expected in instruments structured in factors (Little, Cunningham, Shahar, \& Widaman, 2002). Similar results were observed in a sample of the Ribeirinhos population in Amazonas, Brazil, in which the internal consistency of the scale was satisfactory, which did not occur in the dimensions "physical pain", "psychological limitation" and "handicap" (Cohen-Carneiro et al., 2010). In 12-year-old students from the city of Sabará-MG, the internal consistency of the scale was satisfactory, but the analysis of the seven dimensions showed a Cronbach alpha value below the acceptable level (Ferreira et al., 2004).

The short version of the OHIP-14, showing less than a third of the items of the original instrument, may have contributed to decrease its reliability (Ferreira et al., 2004). The consistency of a scale decreases as the number of items becomes smaller (Deshpande \& Nawathe, 2015; Slade, 1997). It is also worth mentioning the interference of the translation process of the items of the instrument to other languages (Slade, 1997).

The items that compose the OHIP-14 were appropriately related to the total score, with item-total correlations above 0.30 , suggesting reliability, since, in a reliable scale, all items should correlate with the total. These findings were also verified in an investigation performed with adults in Spain (Montero-Martín et al., 2009), however, they disagree from what was observed when this instrument was applied in adults in a national study (Cohen-Carneiro et al., 2010), which may be related to the particularities of the sample.

Reproducibility verified by the reliability of the testretest was adequate in most items of the instrument, which agrees with previous data published in literature (RenerSitar et al., 2008). This finding indicated good stability of the OHIP-14 throughout the studied period, supporting the psychometric recommendations (Marôco, 2014).

The results of this study showed that the OHIP-14, applied in adolescents, has construct validity, reliability and 
criterion validity, subsidizing its use in studies assessing the self-perception of oral health for this population. However, the use of the instrument by dimensions must be performed with consideration, considering the values obtained in the convergent validity and in the internal consistency analysis.

The OHIP-14 proved to be a valid and reliable instrument for the assessment of the impact of oral health and might be used as a complementary tool to the traditional methods of assessing the need for dental treatment in adolescence. It is an instrument that might help in the exploration of oral health needs and in the elaboration of strategies, in order to reduce the development of diseases and to promote oral health with positive impact on the quality of life (Afonso $\&$ Silva, 2015). The use of OHIP-14 in adolescents, before the satisfactory evidences of validities, might help the public policies of oral health in this age group, since the knowledge of self-perception of oral health is essential to meet the demands of the population and to reduce the inequalities in dental health (Gabardo et al., 2015).

It is worth highlighting that the items of the OHIP-14 are in ordinal scale with five options of answers, which, in theory, statistics such as variance and covariance, in which the factor analysis is based on, are devoid of numerical meaning and violate the assumption of normality. However, the use of variables in ordinal scale in factor analysis is frequent, since the Likert format is one of the most used in most scales in the field of Social Sciences. As the number of response alternatives increases in the scales, both the reliability and validity improve (Lozano, García-Cueto, \& Muñiz, 2008).

This investigation is important in the field of Psychology, since it addresses the psychometric assessment of a measuring instrument of the self-perception of oral health. This topic arouses the interest of scholars of this complex, dynamic and multidimensional construct. We expect that this study contributes to the practice of the professional who works with adolescents, by showing the possibility of use of a validated instrument for this population that assesses the impact of the self-perception of oral health on the quality of life. In addition, the results of the use of the validated instrument for this age group might subsidize public policies for the promotion of oral health.

\section{References}

Afonso, A., Silva, I., Meneses, R., \& Frias-Bulhosa, J. (2017). Qualidade de vida relacionada com a saúde oral: Validação Portuguesa de ohip-14. Psicologia, Saúde \& Doenças, 18(2), 374-388. doi:10.15309/17psd180208

Afonso, A. C., \& Silva, I. (2015). Qualidade de vida relacionada com saúde oral e variáveis associadas: Revisão integrativa [Oral health-related quality of life and associated variables: Integrative review]. Psicologia, Saúde \& Doenças, 16(3), 311-330. Retrieved from http://www. scielo.mec.pt/scielo.php?script=sci_arttext\&pid=S1645$00862015000300004 \& \operatorname{lng}=$ pt\&tlng $=$ pt
Arbuckle, J. A. (2014). IBM SPSS Amos 23 user's guide. Chicago, IL: IBM SPSS. Retrieved from ftp://public.dhe. ibm.com/software/analytics/spss/documentation/amos /23.0/en/Manuals/IBM_SPSS_Amos_User_Guide.pdf

Aubert, J., Sanchéz, S., Castro, R., Monsalves, M. J., Castillo, P., \& Moya, P. (2014). Calidad de vida relacionada con salud oral en mayores de 14 años en la Comunidad San Juan Bautista, Isla Robinson Crusoe, Chile [Quality of life related to oral health in subjects 14 years or older, San Juan Bautista Community, Robinson Crusoe Island, Chile]. International Journal of Odontostomatology, 8(1), 141-145. doi:10.4067/ S0718-381X2014000100019

Awad, M., Al-Shamrany, M., Locker, D., Allen, F., \& Feine, J. (2008). Effect of reducing the number of items of the oral health impact profile on responsiveness, validity and reliability in edentulous populations. Community Dentistry and Oral Epidemiology, 36(1), 12-20. doi:10.1111/j.1600-0528.2006.00364.x

Barbosa, T. D. S., Mialhe, F. L., Castilho, A. R. F., \& Gavião, M. B. D. (2010). Qualidade de vida e saúde bucal em crianças e adolescentes: Aspectos conceituais e metodológicos [Quality of life and oral health in children and adolescents: Conceptual and methodological aspects]. Physis: Revista de Saúde Coletiva, 20(1), 283-300. doi:10.1590/S010373312010000100015

Bauman, J. M., Souza, J. G. S., Bauman, C. D., \& Flório, F. M. (2018). Aspectos sociodemográficos relacionados à gravidade da maloclusão em crianças brasileiras de 12 anos. Ciência \& Saúde Coletiva, 23(3), 723-732. doi:10.1590/1413-81232018233.07702016

Campos, J. A. D. B., Carrascosa, A. C., Zucoloto, M. L., \& Maroco, J. (2014). Validation of a measuring instrument for the perception of oral health in women. Brazilian Oral Research, 28(1), 1-7. doi:10.1590/1807-3107BOR-2014. vol28.0033

Cohen-Carneiro, F., Rebelo, M. A. B., Souza-Santos, R., Ambrosano, G. M. B., Salino, A. V., \& Pontes, D. G. (2010). Psychometric properties of the OHIP-14 and prevalence and severity of oral health impacts in a rural riverine population in Amazonas State, Brazil. Cadernos de Saúde Pública, 26(6), 1122-1130. doi:10.1590/S0102311X2010000600006

Colussi, P. R. G., Hugo, F. N., Muniz, F. W. M. G., \& Rösing, C. K. (2017). Oral health-related quality of life and associated factors in Brazilian adolescents. Brazilian Dental Journal, 28(1), 113-120. doi:10.1590/01036440201701098

Deshpande, N. C., \& Nawathe, A. A. (2015). Translation and validation of Hindi version of oral health impact profile-14. Journal of Indian Society of Periodontology, 19(2), 208-210. doi:10.4103/0972-124X.145806 
Ferreira, C. A., Loureiro, C. A., \& Araújo, V. E. (2004). Propriedades psicométricas de indicador subjetivo aplicado em crianças [Psycometrics properties of subjetive indicator in children]. Revista de Saúde Pública, 38(3), 445-452. doi:10.1590/S003489102004000300016

Gabardo, M. C. L., Moysés, S. J., Moysés, S. T., Olandoski, M., Olinto, M. T. A., \& Pattussi, M. P. (2015). Multilevel analysis of self-perception in oral health and associated factors in Southern Brazilian adults: A cross-sectional study. Cadernos de Saúde Pública, 31(1), 49-59. doi:10.1590/0102-311X00037814

Hair, J. F., Jr., Black, W. C., Babin, B. J., Anderson, R. E., \& Tatham, R. L. (2009). Análise multivariada de dados [Multivariate analysis of data] (A. S. Sant'Anna, Trad., 6a ed.). Porto Alegre, RS: Bookman.

Hutz, C. S., Bandeira, D. R., \& Trentini, C. M. (2015). Psicometria [Psychometrics]. Porto Alegre, RS: Artmed.

Landis, J. R., \& Koch, G. G. (1977). The measurement of observer agreement for categorical data. Biometrics, 33(1), 159-174. doi:10.2307/2529310

Little, T. D., Cunningham, W. A., Shahar, G., \& Widaman, K. F. (2002). To parcel or not to parcel: Exploring the question, weighing the merits. Structural Equation Modeling: A Multidisciplinary Journal, 9(2), 151-173. doi: 10.1207/S15328007SEM0902_1

Lozano, L. M., García-Cueto, E., \& Muñiz, J. (2008). Effect of the number of response categories on the reliability and validity of rating scales. Methodology: European Journal of Research Methods for the Behavioral and Social Sciences, 4(2), 73-79. doi:10.1027/16142241.4.2.73

Marôco, J. (2014). Análise de equações estruturais: Fundamentos teóricos, software \& aplicações [Structural equation analysis: Theoretical fundamentals, software \& applications] (2a ed.). Lisboa, Portugal: Report Number.

Montero-Martín, J., Bravo-Pérez, M., Albaladejo-Martínez, A., Hernández-Martín, L. A., \& Rosel-Gallardo, E. M. (2009). Validation the oral health impact profile (OHIP14sp) for adults in Spain. Medicina Oral, Patología Oral y Cirugía Bucal, 14(1), E44-50. Retrieved from http:// www.medicinaoral.com/odo/volumenes/v1i1/01.pdf

Norusis, M. J. (2012). IBM SPSS Statistics 19 advanced statistical procedures companion. Upper Saddle River, NJ: Prentice Hall.

Oliveira, D. C., Ferreira, F. M., Morosini, I. A. C., TorresPereira, C. C., Martins Paiva, S., \& Fraiz, F. C. (2015). Impact of oral health status on the oral healthrelated quality of life of Brazilian male incarcerated adolescents. Oral Health \& Preventive Dentistry, 13(5), 417-25. doi:10.3290/j.ohpd.a33922
Papagiannopoulou, V., Oulis, C. J., Papaioannou, W., Antonogeorgos, G., \& Y fantopoulos, J. (2012). Validation of a Greek version of the oral health impact profile (OHIP-14) for use among adults. Health and Quality of Life Outcomes, 10(1), 7. doi:10.1186/1477-7525-10-7

Pasquali, L. (2009). Psychometrics. Revista da Escola de Enfermagem da USP, 43(1), 992-999. doi:10.1590/ S0080-62342009000500002

Peres, K. G., Cascaes, A. M., Leão, A. T. T., Côrtes, M. I. S., \& Vettore, M. V. (2013). Sociodemographic and clinical aspects of quality of life related to oral health in adolescents. Revista de Saúde Pública, 47(Supl. 3), 19-28. doi:10.1590/S0034-8910.2013047004361

Rener-Sitar, K., Petričević, N., Čelebić, A., \& Marion, L. (2008). Psychometric properties o f Croatian and Slovenian short form of oral health impact profile questionnaires. Croatian Medical Journal, 49(4), 536-544. doi:10.3325/cmj.2008.4.536

Reppold, C. T., Gurgel, L. G., \& Hutz, C. S. (2014). $\mathrm{O}$ processo de construção de escalas psicométricas [The process of construction of psychometric scales]. Avaliação Psicológica, 13(2), 307-310. Retrieved from: http://pepsic.bvsalud.org/scielo.php?script=sci_ arttext\&pid=S1677-04712014000200018 \&lng=pt

Silva, L. F. G., Thomaz, E. B. A. F., Freitas, H. V., Pereira, A. L. P., Ribeiro, C. C. C., \& Alves, C. M. C. (2016). Impact of malocclusion on the quality of life of Brazilian adolescents: A population-based study. PloS One, 11(9), e0162715. doi:10.1371/journal.pone.0162715

Silveira, M. F., Marôco, J.P., Freire, R. S., Martins,A. M.E.D. B., \& Marcopito, L. F. (2014). Impact of oral health on physical and psychosocial dimensions: An analysis using structural equation modeling. Cadernos de Saúde Pública, 30(6), 1169-1182. doi:10.1590/0102-311X00072013

Skośkiewicz-Malinowska, K., Kaczmarek, U., Ziętek, M., \& Malicka, B. (2015). Validation of the Polish version of the oral health impact profile-14. Advances in Clinical and Experimental Medicine, 24(1), 129-137. doi:10.17219/acem/35476

Slade, G. D. (1997). Derivation and validation of a short-form oral health impact profile. Community Dentistry and Oral Epidemiology, 25(4), 284-290. doi:10.1111/j.1600-0528.1997.tb00941.x

Tuchtenhagen, S., Bresolin, C. R., Tomazoni, F., da Rosa, G. N., Del Fabro, J. P., Mendes, F. M., ... Ardenghi, T. M. (2015). The influence of normative and subjective oral health status on school children's happiness. BMC Oral Health, 15(1), 15. doi:10.1186/1472-6831-15-15

Vyas, S., Nagarajappa, S., Dasar, P. L., \& Mishra, P. (2018). Cross-cultural adaptation and psychometric evaluation of oral health impact profile among school teacher community. Journal of Education and Health Promotion, 7, 4. doi:10.4103/jehp.jehp_28_17 
Ware, J. E., Jr., Kosinski, M., \& Keller, S. D. (1996). A 12Item Short-Form Health Survey: Construction of scales and preliminary tests of reliability and validity. Medical Care, 34(3), 220-233. doi:10.2307/3766749

Zucoloto, M. L., Marôco, J., \& Campos, J. A. D. B. (2014). Psychometric properties of the oral health impact profile and new methodological approach. Journal of Dental Research, 93(7), 645-650. doi:10.1177/0022034514533798

Marise Fagundes Silveira is a Professor of the Universidade Estadual de Montes Claros, Montes Claros-MG, Brazil.

Lucinéia Pinho is a Professor of the Universidade Estadual de Montes Claros, Montes Claros-MG, Brazil.

Maria Fernanda Santos Figueiredo Brito is a Professor of the Universidade Estadual de Montes Claros, Montes ClarosMG, Brazil.

\section{Authors' Contribution:}

All authors made substantial contributions to the conception and design of this study, to data analysis and interpretation, to the manuscript revision and approval of the final version. All authors assume public responsibility for content of the manuscript.

Received: Nov. 23, 2016

1st Revision: Jun. 08, 2017

2nd Revision: Mar. 20, 2018

3rd Revision: Jun. 06, 2018

Approved: Jun. 09, 2018

How to cite this article:

Silveira, M. F., Pinho, L., \& Brito, M. F. S. F. (2019). Validity and reliability of the instrument oral health impact profile (OHIP-14) in adolescents. Paidéia (RibeirãoPreto), 29, e2921. doi:http://dx.doi.org/10.1590/1982-4327e2921 